\title{
Hyperglycemic memory in diabetic cardiomyopathy
}

\author{
Jiabing Zhan, Chen Chen, Dao Wen Wang (凶), Huaping Li (ه) \\ Division of Cardiology, Department of Internal Medicine, Tongji Hospital, Tongji Medical College, Huazhong University of Science and \\ Technology, Wuhan 430030, China; Hubei Key Laboratory of Genetics and Molecular Mechanisms of Cardiological Disorders, Wuhan \\ 430030, China \\ (C) The Author(s) 2021. This article is published with open access at link.springer.com and journal.hep.com.cn
}

\begin{abstract}
Cardiovascular diseases account for approximately $80 \%$ of deaths among individuals with diabetes mellitus, with diabetic cardiomyopathy as the major diabetic cardiovascular complication. Hyperglycemia is a symptom that abnormally activates multiple downstream pathways and contributes to cardiac hypertrophy, fibrosis, apoptosis, and other pathophysiological changes. Although glycemic control has long been at the center of diabetes therapy, multicenter randomized clinical studies have revealed that intensive glycemic control fails to reduce heart failure-associated hospitalization and mortality in patients with diabetes. This finding indicates that hyperglycemic stress persists in the cardiovascular system of patients with diabetes even if blood glucose level is tightly controlled to the normal level. This process is now referred to as hyperglycemic memory (HGM) phenomenon. We briefly reviewed herein the current advances that have been achieved in research on the underlying mechanisms of HGM in diabetic cardiomyopathy.
\end{abstract}

Keywords diabetes; diabetic cardiomyopathy; hyperglycemic memory

\section{Introduction}

Diabetes is one of the major diseases that threaten human health, with a global prevalence of $4 \%-17 \%$. According to a 2019 report of the International Diabetes Federation, 351.7 million people of working age (20-64 years) had diagnosed or undiagnosed diabetes worldwide. This number is expected to increase to 417.3 million by 2030 , bringing a heavy medical and economic burden to the society. A recent epidemiological research showed that the prevalence of diabetes among Chinese adults has reached $11.6 \%$. Diabetes can cause various severe complications involving many vital organs, such as heart, brain, kidneys, and eyes. Among them, cardiovascular complications result in the highest rate of disability and mortality, accounting for nearly $80 \%$ of deaths due to diabetes complications. Framingham et al. have demonstrated that the incidence of heart failure is substantially higher in patients with diabetes than that in patients without this disease, with a twofold increase in males and a fivefold increase in females compared with age-matched indivi-

Received December 18, 2020; accepted June 25, 2021

Correspondence: Dao Wen Wang, dwwang@tjh.tjmu.edu.cn; Huaping Li, huapingli_tj@126.com duals. In fact, diabetes can indirectly lead to heart failure by promoting hypertension and coronary heart disease [1]. Although diabetic vascular dysfunction is considered as the leading cause of heart failure in patients with diabetes [2], recent studies have established that diabetes is an independent risk factor of heart failure, even after controlling for coronary artery disease and hypertension [3-5].

The concept of diabetic cardiomyopathy was proposed as early as 1974 by Robert I. Hamby. It was defined as the appearance of abnormal myocardial structure and performance in the absence of hypertension, coronary heart disease, severe valvular disease, and other conventional cardiovascular risk factors in individuals with diabetes [6]. Subsequent studies have found that diabetic cardiomyopathy is characterized by cardiac diastolic dysfunction and vascular/microvascular function impairment in the early stage, systolic dysfunction in the later stage, and clinical heart failure, with pathological features that include cardiac hypertrophy, interstitial fibrosis, increased capillary basement membrane thickness, capillary microangioma, and decreased capillary density in the end stage [7-9]. Notably, the typical definition of diabetic cardiomyopathy comprises structural and functional abnormalities of the myocardium in patients with diabetes without coronary artery disease or hypertension [10]. Obviously, this type of 
cardiomyopathy should also be present in patients with diabetes with coronary artery disease and/or hypertension, although separately assessing the contribution of diabetic cardiomyopathy to overall ventricular dysfunction in such cases is difficult [11]. Clinically, requiring the absence of coronary artery disease, hypertension, or any other form of cardiac disease when a diagnosis of diabetic cardiomyopathy is made seems unrealistic. Therefore, researchers have recently proposed that "diabetic cardiomyopathy" should be defined as "cardiac abnormalities not wholly explained by other cardiovascular or non-cardiovascular causes and likely to be due to diabetes" $[12,13]$.

Although the pathological mechanisms underlying diabetic cardiomyopathy has not been precisely described thus far, several mechanisms have been speculated to account for the progress of diabetic cardiomyopathy, including decreased mitochondrial respiration and pyruvate dehydrogenase activity, accumulation of free radical species, and malfunction of cardiac contractile and intracellular $\mathrm{Ca}^{2+}$ regulatory proteins [14]. Interestingly, diabetes seems to abolish the effect of "female advantage" in cardiovascular system, and it is presented as a more serious impairment of myocardial electromechanical function and more prominent neuroregulatory system disorders in women patients suffering from diabetic cardiomyopathy compared with age-matched men [14]. The prevalence of diabetic cardiomyopathy is increasing in parallel with the increase in the number of patients with diabetes around the world, but no effective or targeted treatment specific for diabetic cardiomyopathy has been developed to date, prompting the research community to devise new therapies that target different pathways $[15,16]$.

Hyperglycemia has long been believed to be a major factor that contributes to the development and progression of diabetic cardiomyopathy by activating multiple signaling pathways, such as the protein kinase $\mathrm{C}$ (PKC), MAPK, NF- $\mathrm{kB}$, SGLT2, O-GlcNAc, and CREM signaling pathways, which subsequently leads to cardiac structural remodeling, cardiomyocyte apoptosis, and activation of systemic and tissue RAAS [8,17]. Thus, glycemic control has been considered as one of the most important therapeutic approaches in the prevention and treatment of diabetes complications [18-23]. However, multiple recent large-scale studies have revealed that intensive glycemic control fails to improve the overall cardiovascular outcomes in patients with diabetes. A meta-analysis conducted by Turnbull et al. analyzed several clinical trials (ACCORD, ADVANCE, VADT, and UKPDS) and concluded that intensive glycemic control does not reduce myocardial infarction events and is insufficient to lower the risk of heart failure in patients with diabetes [24,25]. These studies suggested that patients with diabetes are still prone to cardiovascular complications even after intensive blood glucose control, indicating that transient hyperglycemia stress persists, a condition that is now referred to as "hyperglycemic memory" (HGM) phenomenon. In this review, we will summarize the underlying mechanisms of HGM that have been recently revealed. Thus, this study will provide a theoretical and experimental basis for the development of new strategies for diabetic cardiomyopathy.

\section{Advanced glycation end products}

Advanced glycation end products (AGEs) are a heterogeneous group of molecules produced by Maillard reaction, in which the reactive carbonyls in glucose, fructose, or their metabolites, such as methylglyoxal and deoxyglucosone, nonenzymatically react with the amine groups in proteins, nucleotide bases, or fatty acids, followed by further modification, such as dehydration, oxidation, rearrangement, or other reactions, to finally form AGEs [26,27]. Accumulation of AGEs and upregulation of AGE receptors (RAGEs) promote the onset of diabetic cardiomyopathy in streptozocin (STZ)-induced diabetic mice, whereas treatment with the AGE formation inhibitor benfotiamine ameliorates cardiac dysfunction [28]. AGEs induced by hyperglycemia might alter the functional properties of many important proteins, including vital matrix components. For example, AGE formation in type IV collagen induces an irregular crosslink of these molecules instead of generating the normal network-like structure by enzyme lysyl oxidase [29]. AGE formation in laminin decreases its binding to type IV collagen and heparan sulfate proteoglycan (HSPG), resulting in the absence of HSPG in the basement membrane of glomeruli and a compensatory overproduction of other matrix components in diabetic rats [29]. These alterations in extracellular matrix together reduces the compliance of the heart, leading to diastolic dysfunction. Aside from matrix components, AGEs can further directly activate multiple signaling pathways or bind to specific cell-surface receptors, such as RAGEs, a process that subsequently promotes the progress of various pathological changes, such as inflammation, production of reactive oxygen species (ROS), autophagy, or apoptosis, leading to cardiac remodeling and cardiac dysfunction [29].

Accumulated AGEs contribute to different pathological changes in diverse cell types and organs. Oldfield et al. [30] found that in fibroblasts, AGE/RAGE signals stimulate the expression of the inflammation-related gene TGF- $\beta$ and promote the proliferation of fibroblasts and the synthesis of matrix proteins. Excessive collagen deposition leads to myocardial fibrosis and a decrease in cardiac compliance and function [30]. Jin et al. [31] suggested that AGE stimulation remarkably increases RAGE expression in macrophages, promotes macrophage differentiation to M1 phenotype, and enhances the expression of several proinflammatory mediators, such as IL-6, TNF, and the 
NF- $\mathrm{BB}$ pathway. Notably, by secreting multiple proinflammatory cytokines and via intercellular interactions, activated macrophages can further promote the proliferation and secretion of fibroblasts. Bucala et al. [32] found that AGEs can quench nitric oxide (NO), the major active constituent of endothelium-derived relaxing factor, both in vitro and in vivo. They further confirmed that endothelium-dependent relaxation of ascending aorta in diabetic rats is damaged by the accumulation of AGEs in endothelial cells. Accordingly, inhibition of AGE formation by aminoguanidine, a hydrazine-like compound, ameliorates vasodilatory impairment by preserving endothelium-derived NO [32]. Schmidt et al. [33] found that the exposure of cultured human endothelial cells to AGEs can induce the expression of vascular cell adhesion molecule-1 (VCAM-1). Therefore, it might accelerate atherogenesis by enhancing the interactions between endothelium and circulating monocytes.

With regard to AGEs in cardiomyocytes, a recent study revealed that AGE exposure impairs the binding of FK506 binding protein 12.6 to ryanodine receptor 2 (RyR2), causing elevated intracellular calcium concentration, decreasing mitochondrial membrane potential, and inducing cell apoptosis in myocardium and cultured myocytes [34]. The expression levels of cytochrome $\mathrm{c}$ and active caspase- 3 in rat myocardium and primary myocytes are also elevated by AGE exposure, which together with calcium imbalance, result in cardiac dysfunction [34]. Similarly, glycations of RyR2 and sarco(endo)plasmic reticulum $\mathrm{Ca}^{2+}$-ATPase (SERCA2a) are increased in the hearts of patients and rats with diabetes, leading to perturbed $\mathrm{SR} \mathrm{Ca}^{2+}$ cycling and cardiac dysfunction $[35,36]$. Moreover, AGE accumulation activates PKC in an ROS-dependent manner, triggering mitochondrial dysfunction and subsequent cardiac cell death [37].

Additionally, the AGE-modified form of low density lipoprotein (LDL) reportedly considerably impairs plasma clearance in patients with diabetes in line with decreased LDL receptor binding activity, leading to an elevated circulating LDL level, which is an important mechanism for dyslipidemia, endothelial dysfunction, and accelerated atherogenesis [38]. Zoltowska et al. [39] demonstrated that AGE-modified LDL remarkably enhances platelet aggregation by $32 \%-44 \%$ in response to aggregating agents, such as thrombin, collagen, and ADP, and stimulates cholesterol esterification in monocytes, thereby further contributing to intravascular thrombosis and endothelial dysfunction.

The late stages of Maillard reaction to form AGEs are reportedly irreversible [40], whereas multiple AGEmodified proteins, such as glycated fibrinogen and collagen, are stiffer and less susceptible to biological degradation [41,42]. Therefore, the persistence of accumulated AGEs even after glucose normalization may at least partially explain the HGM phenomenon via various pathways in multiple cell types (Fig. 1), and further studies should attempt to increase the turnover of these abnormally accumulated AGEs and AGE-modified proteins to restore intracellular and circulating physiologic environment.

\section{MicroRNAs}

MicroRNAs are a class of small noncoding RNAs that are 19-25 nucleotides in size that commonly regulate the posttranscriptional silencing of target genes [43]. Mature

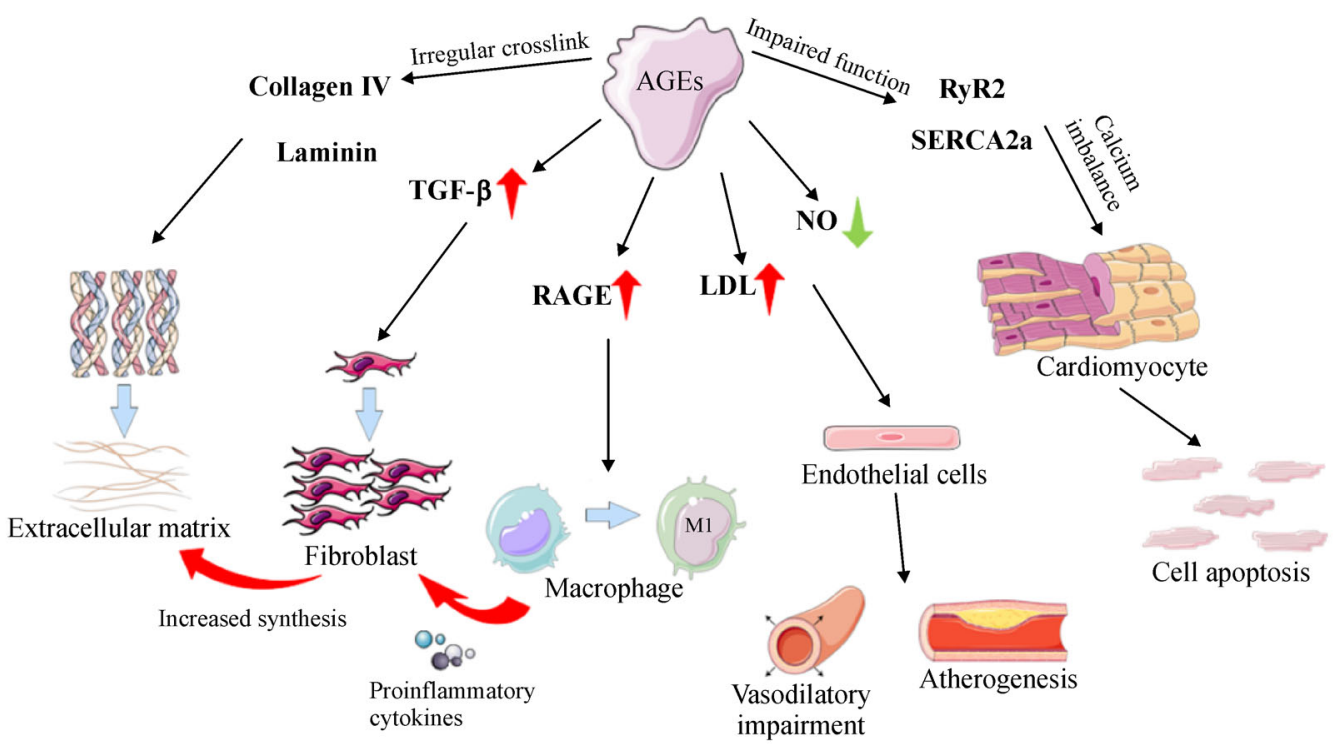

Fig. 1 AGEs promote the process of diabetic cardiomyopathy via various pathways in multiple cell types. 
microRNAs usually mediate the silencing of target genes by binding to the $3^{\prime}$ untranslated region of the target mRNA within RNA-induced silencing complexes, resulting in mRNA degradation or translation inhibition [44]. A single microRNA can target hundreds of mRNAs and influence the expression of numerous genes that might be functionally related [45]. In cardiovascular diseases, microRNAs are reportedly involved in the pathological processes of fibrosis/antifibrosis, hypertrophy, mitochondrial fission, apoptosis, lipid deposition, and oxidative stress [46-48].

Several studies have attempted to identify the roles of miRNAs in the HGM phenomenon. Zhong et al. [46] distinguished three differentially expressed microRNAs (miR-125b, miR-29a-3p, and miR-146a-5p) in the aortas of diabetic rat, regardless of insulin treatment. They further revealed the direct regulatory effects of miR-125b on TNFinduced protein 3 (TNFAIP3) and those of miR-146a-5p on TNF receptor-associated factor 6 (TRAF6) and IL-1 receptor-associated kinase 1 (IRAK1) in human aortic endothelial cells (HAECs). Consistently, the protein levels of these three target genes (TNFAIP3, TRAF6, and IRAK1) are persistently altered in response to transient hyperglycemia, but these changes can be restored by miR$125 \mathrm{~b}$ inhibition or miR-146a-5p overexpression [46]. Strycharz et al. [49] suggested that even a transient exposure to high glucose levels during adipogenesis might induce changes in miRNA expression in mature adipocytes, and the expression profiles are similar to those exposed to chronically high glucose levels. Peng et al. [50] found that high glucose levels induce sustained upregulation of miR-204 and downregulation of sirtuin1 lysine deacetylase (SIRT1) in retinal pigment epithelial cells, both of which contribute to endoplasmic reticulum stress and subsequently to cell apoptosis. These changes can last after replacement with normal glucose levels.

Costantino et al. [51] discovered that 316 microRNAs are dysregulated in the heart of STZ-induced diabetic mice compared with those in the controls, among which 209 are upregulated and 107 are downregulated by $>2.0$-fold. Interestingly, 268 of those dysregulated microRNAs remain altered even after reverting to normoglycemia by insulin treatment. Subsequent ingenuity pathway analysis revealed that a large proportion of these persistently dysregulated miRNAs are involved in processes related to apoptosis (miR-320b, miR-378, and miR-34a), fibrosis (miR-125b, miR-150, miR-199a, miR-29b, and miR30a), hypertrophic growth (miR-1, miR-150, miR-199a, miR133a, miR-214, miR-29a, miR-125b, miR-221, and miR212), autophagy (miR-133a, miR-221, miR-212, and miR30a), oxidative stress (miR-221, miR-146a, miR-34a, miR210, miR-19b, miR-125b, miR27a, and miR-155), and heart failure (miR-423, miR-499, and miR-199a) [51]. These results indicated that glycemic control is insufficient to completely revert the alteration of miRNAs in diabetes, providing a new mechanistic insight into the HGM phenomenon in diabetic cardiomyopathy. Costantino et al. [52] recently confirmed the protective role of JunD, a member of the activated protein-1 family of transcription factors that act as a major gatekeeper against oxidative stress in the pathogenesis of hyperglycemia- or ROS-induced myocardial dysfunction. Furthermore, they revealed that the expression of JunD is epigenetically regulated by hypermethylation in the gene promoter region, as well as by translational repression via miRNA-673, suggesting a complex regulatory mechanism involving microRNAs and epigenetic modifications of critical genes in diabetic cardiomyopathy.

Our previous study revealed that miR-320 expression is elevated in the heart of diabetic mice compared with that in the controls, and this elevation promotes CD36 transcription by facilitating the association of argonaute 2 (Ago2) with RNA polymerase II (Fig. 2). Given that CD36 is known to contribute to fatty acid (FA) uptake, upregulated CD36 results in myocardial lipid deposition and cell apoptosis, subsequently triggering cardiac dysfunction and diabetic myocardiopathy [43]. Sadoshima [53] commented that "the selective upregulation of CD36 transcription by miR-320 shown by Li et al represents a novel mechanism by which lipid uptake is enhanced in the absence of increases in FA oxidation." Sadoshima added that "interestingly, miR-320 forms an RNA-induced silencing complex with Ago2 to promote RNA interference in the cytosol but miR-320 and Ago2 also form a distinct complex, called a RITA complex, in the nucleus, thereby activating transcription" [53]. Moreover, miR-320 is one of those microRNAs that persistently dysregulate in transient hyperglycemia. The lipotoxicity mediated by miRNAs might be one of the underlying mechanisms of the HGM phenomenon in diabetic cardiomyopathy. The issue of whether other miRNA-mediated factors are involved in lipotoxicity and "hyperglycemic memory" is largely unknown and remains to be addressed.

\section{Persistent mitochondrial oxidation stress}

Overproduction of superoxide by the mitochondrial electron-transport chain, which is then converted to other more reactive oxygen free radical species, is another important mechanism in diabetic cardiovascular complications [54-56]. In fact, myocardial glucose-derived pyruvate oxidation is markedly decreased in diabetes because of impaired glucose uptake and cardiomyocyte oxidation [57]. Therefore, the energy fuel in myocytes is mainly derived from FA oxidation. This energy substrate alteration leads to increased $\beta$-oxidation of fatty acyl-coenzyme A (CoA) within the mitochondria and subsequent overproduction of acyl-CoA [58]. However, owing to the uncoupling of mitochondrial enzymes, the tricarboxylic 

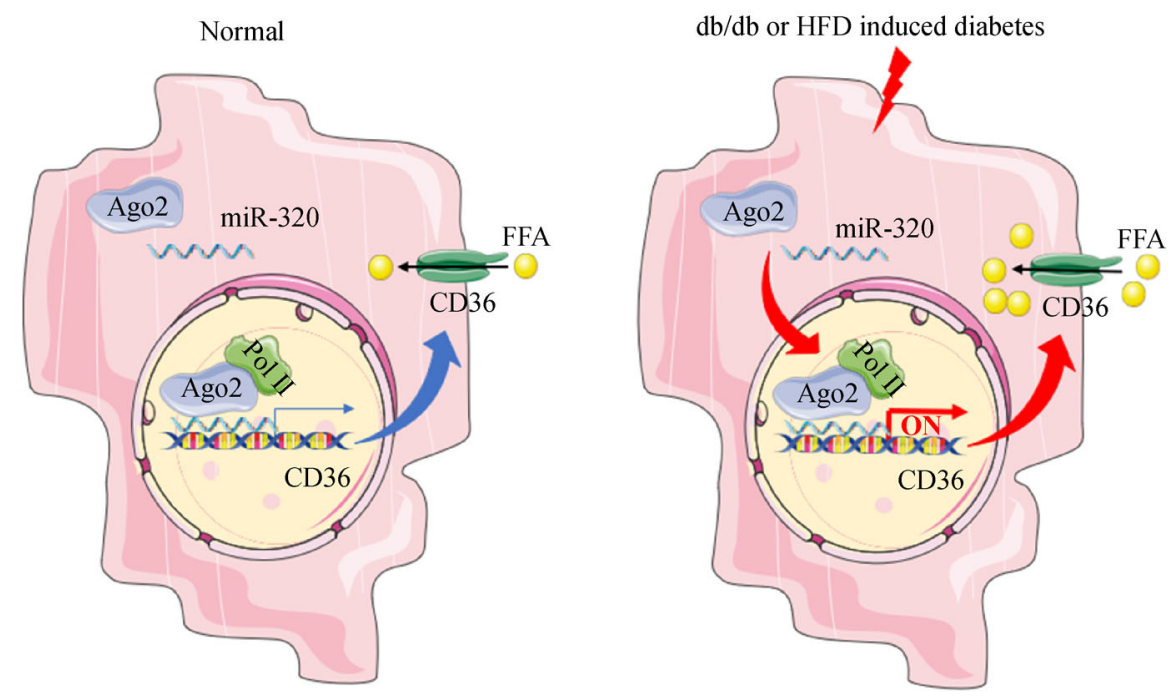

Fig. 2 Elevated miR-320 in the heart of diabetic mice acts in the nucleus to promote CD36 transcription by facilitating the association of argonaute 2 (Ago2) with RNA polymerase II, which increases the FFA uptake of cardiomyocytes and results in myocardial lipid deposition, causing cell apoptosis and cardiac dysfunction. Adapted from reference [37] with permission (OA related license).

acid (TCA) cycle is insufficient to oxidize excessive acyl$\mathrm{CoA}$, leading to the production of toxic intermediates, including ROS $[59,60]$.

By comparison, an increase in acyl-CoA oxidation in the TCA cycle increases the flux of electron donors (NADH and FADH2) into the electron transport chain and consequently elevates the voltage gradient across the mitochondrial membrane. As the voltage gradient reaches a critical threshold, the electron transfer within complex III is blocked, and the electrons would return to coenzyme Q, which donates the electrons to molecular oxygen, thus forming superoxide [61]. Previous studies have determined superoxide as the initial oxygen free radical formed by the mitochondria, which is then converted to other types of ROS [62]. Most importantly, the mitochondria have been demonstrated to be required for the initiation of hyperglycemia-induced superoxide production, which in turn could activate other superoxide production pathways and amplify the original detrimental effects of hyperglycemia, including redox changes, NADPH oxidases, and uncoupled eNOS [63]. In fact, some researchers have even considered enhanced mitochondrial superoxide overproduction as the common step of various mechanisms that underlie hyperglycemia-induced injuries, such as elevated aldose reductase activity, PKC activation, hexosamine pathway flux, AGE formation, and RAGE ligand binding $[63,64]$.

With regard to the HGM phenomenon, the adverse impact of mitochondrial oxidation stress on targeted organs in diabetes displays an enormous potential to persist even after normoglycemia. Ihnat et al. [65] found that multiple markers of oxidative stress, such as BCL-2- associated $\mathrm{X}$ protein, $\mathrm{NAD}(\mathrm{P}) \mathrm{H}$ oxidase subunit $\mathrm{p} 47 \mathrm{phox}$, and 3-nitrotyrosine, which are induced by high glucose treatment, can remain elevated for 1 week after glucose level is normalized in human endothelial cells and ARPE19 retinal cells, which can be interrupted by the blockade of reactive species [65]. Furthermore, the mammalian Shc (Src homology 2 domain containing) gene encodes three different adaptor protein isoforms $\left(\mathrm{p} 46^{\mathrm{Shc}}, \mathrm{p} 52^{\mathrm{Shc}}\right.$, and $\mathrm{p} 66^{\mathrm{Shc}}$ ), but only $\mathrm{p} 66^{\mathrm{Shc}}$ is involved in mitochondrial ROS generation [66]. Targeted mutation of $\mathrm{p} 66^{\text {Shc }}$ reduces the production of intracellular oxidants and increases the resistance to oxidative stress [66], whereas $\mathrm{p} 66^{\mathrm{Shc}-/-}$ mice are protected against vascular and cardiac injuries induced by diabetes by reducing ROS generation and ameliorating hyperglycemia-induced endothelial impairment [67]. Cosentino et al. [68] indicated that in the aortas of diabetic mice and high glucose-treated HAECs, the activation of p66 $6^{\text {Shc }}$ would persist even after reverting to normoglycemia. Specifically, PKC enhances $\mathrm{p} 66^{\text {Shc }}$ expression, whereas $\mathrm{p} 66^{\mathrm{Shc}}$ upregulates $\mathrm{PKC}$ in response to high glucose levels, leading to a detrimental cycle despite the restoration of normoglycemia [68]. Moreover, persistent activation of $\mathrm{p} 66^{\mathrm{Shc}}$ results in ROS overproduction, reduced NO bioavailability, and subsequent cell apoptosis, all of which drives HGM-related cardiovascular complications [68]. Accordingly, gene silencing of $\mathrm{p} 66^{\text {Shc }}$ can inhibit ROS production, restore endothelium-dependent vasorelaxation, and prevent cell apoptosis both in vivo and in vitro, thereby attenuating endothelial dysfunction in diabetes [69]. These studies indicated that persistently activated $\mathrm{p} 66^{\text {Shc }}$ has a critical role in the HGM phenomenon. 
Lee et al. [70] recently revealed a vicious cycle involving transglutaminase 2 activation and ROS generation in the aortic endothelium of mice exposed to transient hyperglycemia, and this cycle can be disrupted by oral administration of either Cys (a type of TGase inhibitor) or $\mathrm{N}$-acetylcysteine, an ROS scavenger.

NADPH oxidase is remarkably activated in the cardiomyocytes of diabetic Wistar rats, leading to ROS overproduction and myocardial apoptosis [71]. Our recent study also found that the excessive ROS generated in the mitochondria is regulated by miR-92a-2-5p and let-7b-5p in the heart of diabetic mice. Specifically, a decrease in miR-92a-2-5p and let-7b-5p in the mitochondria downregulates the expression of mitochondrial gene cytochrome-b (mt-Cytb), a critical protein in the process of ROS generation, and consequently increases mitochondrion-derived ROS under diabetes conditions, which can be rescued by the re-expression of miR-92a-2-5p and let$7 b-5 p$ in cardiomyocytes [72]. Interestingly, the let-7 family has also been demonstrated to be involved in the HGM phenomenon [51]. In fact, ROS overproduction and disrupted redox balance have been extensively reported to mediate the expression of various microRNAs [73]. Kim et al. [74] indicated that miR-210 is upregulated by various sources of ROS in adipose-derived stem cells, whereas $\mathrm{He}$ et al. [75] revealed that miR-199a and miR-125b are inhibited by ROS via hypermethylation in their promoter regions. Therefore, mitochondrion-derived ROS along with microRNAs might possibly constitute a vicious cycle that can persist even after restoration of normoglycemia, thereby contributing to the pathogenesis of HGM in diabetic cardiomyopathy.

Importantly, mitochondrial DNA (mtDNA) is prone to enhanced oxidative damage because it lacks a DNA repair mechanism and owing to its special subcellular location wherein it is too close to the electron transport chain [76]. Given that mtDNA encodes several essential protein subunits of the oxidative phosphorylation system, persistently impaired mtDNA as induced by hyperglycemiaderived superoxide would result in further ROS production, which might be the potential mechanisms underlying sustained diabetic cardiomyopathy.

\section{DNA methylation and histone protein modification}

DNA methylation and histone protein modification also play an important role in the HGM phenomenon in diabetic cardiomyopathy [77,78]. Cytosine-phosphate-guanine $(\mathrm{CpG})$ hypomethylation in the promoter region of protein-coding genes generally results in transcriptional activation. By contrast, methylation of $\mathrm{CpG}$ sites by DNA methyl transferase (DNMT) promotes the binding of promoter regions with methyl-CpG binding domain proteins instead of transcription factors, and the former in turn recruits histone deacetylases, leading to transcriptional repression [77]. Metabolism plays a central role in DNA methylation. Demethylation is regulated by teneleven translocation (TET) family enzymes, which utilize the TCA cycle intermediate $\alpha$-ketoglutarate to remove methyl groups [79]. Succinate acts as a competitor of $\alpha-$ ketoglutarate to inhibit TET activity [80]. Succinate levels are increased in type 2 diabetes [81]. Therefore, metabolic perturbations regulate the activity of enzymes involved in the balance between DNA methylation and demethylation [82].

Histones are subject to diverse post-translational modifications, which include acetylation and methylation of lysines and arginines, phosphorylation of serines and threonines, and ubiquitylation and sumoylation of lysines [83]. Foremost among them are acetylation and methylation. In general, acetylation of histones (H2A, H2B, H3, and H4) in different lysine sites is usually associated with transcriptional activation [84]. Numerous studies have revealed that in diabetes, the expression levels of various genes are regulated by acetylation, but these can be reversed by the application of histone acetyltransferases (HATs) or histone deacetylases (HDACs), thus attenuating cardiac dysfunction [85-87]. Hyperglycemia decreases the activity of glucose-6-phophate dehydrogenase [88], which results in increased global levels of $\mathrm{H} 3$ and $\mathrm{H} 4$ acetylation [89]. An altered metabolic environment and an abnormal accumulation of intermediates (such as CoA derivatives, free $\mathrm{CoA}, \mathrm{NAD}^{+}$, and NADH) would stimulate or inhibit the activity of HATs or HDACs, thereby changing the states of histone acetylation. The enzymes that regulate histone acetylation are HATs and HDACs, and these enzymes can also directly acetylate or deacetylate various transcription factors and regulatory proteins aside from histones [90]. Yu et al. [91] recently found that STZinduced diabetes in mice and high glucose environment for neonatal mouse cardiomyocytes can suppress Sirt3 (a member of HDACs), thereby reducing Foxo3A deacetylation and subsequent Parkin expression. Suppressed Sirt3Foxo3A-Parkin expression leads to impaired mitophagy and cardiac contractile dysfunction [91].

A global analysis of histone code modifications in cardiac mesenchymal cells (CMSCs) derived from patients with diabetes revealed a greater reduction in histone 3 lysine 9 acetylation (H3K9Ac) and histone 3 lysine 14 acetylation - compared with the CMSCs derived from patients without diabetes [92]. Given that the CMSCs used in this study were cultured in the presence of normal glucose levels, sustained alteration of histone acetylation state might be involved in the HGM phenomenon [92].

Moreover, an increase in $\beta$-oxidation of FAs leads to upregulated acetyl-CoA levels within the mitochondria. 
Although acetyl-CoA is the only known substrate for acetylation in most eukaryotes, abundant acetyl-CoA and high $\mathrm{pH}$ (which has been shown to enhance the ratio of neutral and nucleophilic forms of lysine residues) lead to substantial spontaneous mitochondrial protein acetylation via both enzymatic and nonenzymatic mechanisms [93]. Irregular hyperacetylation reportedly inhibits many catalytic activities of mitochondrial enzymes [94]. Hyperacetylation of some cytoplasmic proteins, such as $\mathrm{p} 66^{\text {Shc }}$, has been demonstrated to promote its phosphorylation at Ser36 and its translocation to the mitochondria, which then increase ROS production through the generation of hydrogen peroxide [95]. However, the question of whether nonnuclear proteins are acetylated requires further study.

Methylation in the lysine residue of histone is a considerably more complex process as it involves diverse conserved lysine loci, such as lysine 4 of H3 (H3K4), lysine 9 of H3 (H3K9), and lysine 20 of H4 (H4K20), as well as different methylation patterns, including mono-, di-, or tri-methylation, all of which usually cluster within specific regions and lead to the reorganization of chromosomes into different structural and functional domains [77]. Moreover, histone methylation processes are regulated by multiple enzymes, including histone methyltransferases (HMTs) and histone demethylases (HDMs or HDMTs). Recent studies have found that high glucose levels decrease lysine methyltransferase 5A (KMT5A) and cAMP response element binding protein. Thus, high glucose levels reduce histone $\mathrm{H} 4$ lysine 20 methylation (H4K20me1, a downstream target of KMT5A) in protein tyrosine phosphatase 1B promoter, which then augments expressional activity in human umbilical vein endothelial cells (HUVECs) [96]. Wang et al. [97] also revealed that high glucose levels inhibit SET8 (a methyltransferase) expression and H4K20me1 in the microtubule affinity regulating kinase 4 (MARK4) promoter region, resulting in induced MARK4 expression and NLRP3 inflammasome activation. Of note, SET8, along with LSD1 (one of the HDMs), controls the protein stability of DNMT1 via methylation-mediated, ubiquitin-dependent degradation, consequently influencing DNA methylation [98]. In conclusion, a high glucose level itself can alter the expression and activity of multiple histone modification enzymes and accordingly influence DNA and histone methylation states.

Miao et al. [99] utilized the samples from The Diabetes Control and Complications Trial (DCCT) to profile H3K9Ac-, H3K4Me3-, and H3K9Me2-linked gene promoter regions in blood monocytes obtained from 30 DCCT conventional treatment group subjects (case subjects) and 30 DCCT intensive treatment group subjects (control subjects). They found that the case subjects had a substantially higher average number of regions enriched with H3K9Ac than the control subjects. Of note, the genes universally hyperacetylated in promoter regions were found to be enriched to diabetes-related pathways, including ROS, apoptosis, and macrophage and dendritic cell functions [99]. Chen et al. [100] compared the DNAme profiles in genomic DNA of whole blood isolated at EDIC Study baseline from 32 cases (previous DCCT conventional therapy group subjects) with those of 31 controls (previous DCCT intensive therapy group). They found a set of differentially methylated loci despite the lack of notable difference in HbAlc levels between cases and controls [100]. Olsen et al. [101] used zebrafish, which can spontaneously recover from diabetes via pancreatic $\beta$-cell regeneration, to perform $\mathrm{CpG}$ island methylation and genome-wide microarray expression analysis with daughter tissues that were never exposed to hyperglycemia. Interestingly, they discovered the persistence of hyperglycemia-induced global DNA hypomethylation in a subset of loci associated with abnormally expressed genes in these daughter tissues, and this hypomethylation might explain the impaired caudal fin regeneration to the same extent as that of diabetic zebrafish [101], implicating DNA methylation as a potential contributor to the HGM phenomenon.

El-Osta et al. [102] found that in aortic endothelial cells, exposure to transient and prior hyperglycemia causes sustained epigenetic changes in the NF- $\mathrm{KB}$ subunit $\mathrm{p} 65$

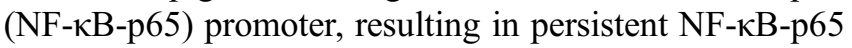
gene expression. Specifically, transient hyperglycemia results in ROS overproduction by the mitochondrial electron transport chain, thereby increasing H3K4 monomethylation ( $\mathrm{H} 3 \mathrm{~K} 4 \mathrm{me})$ in the NF- $\mathrm{KB}-\mathrm{p} 65$ promoter via recruitment of histone methyltransferase Set7 [103]. Another important epigenetic mechanism that underlies sustained NF-kB-p65 activation is the distinct and persistent $\mathrm{H} 3 \mathrm{~K} 9$ demethylation (including dimethylation and trimethylation) in proximal p65 promoter, which is mediated by hyperglycemia-induced recruitment of the methyl-lysine eraser LSD1 [102]. H3K4me appears to be a crucial post-translational modification that triggers gene expression. Hyperglycemic stress increases H3K4 monomethylation in NF- $\mathrm{kB}-\mathrm{p} 65$ promoter, driving proinflammatory gene expression (such as monocyte chemoattractant protein-1 and VCAM-1, both of which play a major role in the pathogenesis of atherosclerosis), and these alterations cannot be restored by removing from hyperglycemic environment [104-106].

Histone 3 lysine-9 trimethylation (H3K9me3) also appears to be involved in the inflammation process induced by hyperglycemia and the HGM phenomenon [107]. In cardiomyocytes incubated with high glucose levels, the protein levels of the H3K9me3 methyltransferase Suv39h1 are considerably reduced in accordance with the decreased association of Suv39h1 with IL-6 promoter. As a result, a reduction in $\mathrm{H} 3 \mathrm{~K} 9 \mathrm{me} 3$ in the IL-6 promoter region leads to the transcriptional activation of IL-6 [107]. Interestingly, in 
contrast to sustained inflammatory phenotype and epigenetic histone modification, high glucose level-induced myocardial apoptosis and mitochondrial dysfunction are reversible [107]. In high glucose level-treated human THP1 monocytic cells, the transcription factor NF- $\mathrm{BB}$, along with its transcriptional coactivators, including HATs, such as $\mathrm{CBP} / \mathrm{p} 300$ and $\mathrm{p} / \mathrm{CAF}$, are recruited to TNF- $\alpha$ and $\mathrm{COX}$ 2 promoters, which increase the concomitant acetylation of histone $\mathrm{H} 3$ and histone $\mathrm{H} 4$ in the promoter regions, leading to chromosome remodeling and the expression of these proinflammatory genes [108]. Via chromatin immunoprecipitation linked to microarray, Miao et al. [109] unveiled genome-wide $\mathrm{H} 3 \mathrm{~K} 9 \mathrm{me} 2$ patterns in the blood lymphocytes and monocytes from patients with diabetes versus healthy control subjects. They found substantially increased expression of the promoter $\mathrm{H} 3 \mathrm{~K} 9 \mathrm{me} 2$ in autoimmuneand inflammation-related genes, such as p38 mitogenactivated protein kinase, Toll-like receptor, and IL-6 [109].

An aspect that should not be ignored is that the expression levels of epigenetic modification enzymes also reportedly persistently change in response to transient high glucose stimulus. Zheng et al. [110] uncovered that hyperglycemia downregulates NAD-dependent deacetylase sirtuin-1 levels in bovine retinal capillary endothelial cells and returning to normoglycemia fails to rescue SIRT1 reduction. Moreover, elevated glucose levels reduce lysine methyltransferase SET8 proteins in HUVECs, which remain at a low level after switching to normoglycemia [111].

Methylation of histone lysine residues is a class of reasonably stable epigenetic modifications despite a certain degree of reversibility, and it might partly explain the persistent epigenetic changes in the promoter of critical genes after intensive blood glucose control in diabetes. In fact, methylation at different lysine residues in histones has been extensively demonstrated to display differential turnover rates, some of which (such as H3K27me3, H4K20me3, and others) are considerably slower than many other post-translational modifications $[112,113]$. Previous studies have also shown that histone modification enzymes (such as HATs, HDACs, and HMTs) are associated with histones of the type that they can produce, suggesting a positive feedback where modified nucleosomes recruit enzymes that similarly modify nearby nucleosomes, which make it possible for a cluster of nucleosomes to maintain a specific stable modification state, thus causing an "epigenetic memory" [114-116]. Dodd et al. [117] adopted a simplified stochastic model of dynamic nucleosome modification to confirm this mechanism. They found that this mechanism endows a strong bistability to the modification state of a cluster of nucleosomes despite multiple changes in the modification status for each nucleosome. These characteristics of histone modifications suggested that they have a critical role in the mechanisms that underlie the HGM phenomenon.

\section{Other mechanisms}

Patients with diabetes mellitus are often accompanied by multiple metabolic disorders, including abnormal lipid metabolism, obesity, and insulin resistance, all of which cannot be rescued by simple hypoglycemic therapy. For instance, our previous studies have revealed that hyperglycemia increases the myocardial uptake of free FAs by miR-320 by elevating the expression of the FA transporter protein CD36. Lipid deposition results in lipotoxicity in myocytes and consequently induces cell apoptosis, which in turn accelerates the pathogenic progress of diabetic cardiomyopathy $[43,53]$. Interestingly, miR-320 has been demonstrated to be one of the microRNAs that are persistently altered despite normoglycemia [51]. Therefore, the lipotoxicity mediated by miR-320 might provide novel insights into the HGM phenomenon in diabetic cardiomyopathy. Other factors that contribute to cardiac lipotoxicity in diabetes, such as FA transporting proteins other than CD36, elevated glycerol-3-phosphate acyltransferase (GPAT) activity, increased diglyceride acyltransferase, and other cellular pathways that participate in lipotoxic mechanisms, are indeed involved in diabetic cardiomyopathy, but their functions in the HGM phenomenon are yet to be studied.

Low-grade inflammation is commonly observed in various tissues in response to lipid overload, and this condition appears to promote diabetes development via insulin resistance $[118,119]$. Adipose tissues, especially enlarged or dysfunctional adipocytes, are considered the main source of inflammatory factors in obesity, and they attract immune cells and subsequently induce their polarization into a proinflammatory phenotype [118].

The HGM phenomenon has also been observed in clinical settings. Intensive glucose control has been found to have a little effect on reducing the overall risk of cardiovascular complications in individuals with diabetes, and it might be associated with the side effects of hypoglycemic drugs that are extensively used in diabetes therapy [25]. All antihyperglycemic drug therapies can potentially mechanically exert detrimental effects on cardiac dysfunction, thereby precipitating heart failure in patients with diabetes. Moreover, drug-induced hypoglycemia has been shown to cause the activation of sympathetic nervous system and increase the heart rate, both of which contribute to thrombus formation and arrhythmia, thereby further aggravating ventricular remodeling and cardiac dysfunction. For example, insulin can reportedly stimulate the activity of a wide range of sodium transporters, including NHE3, sodium-potassium $(\mathrm{Na} / \mathrm{K})$ 
ATPase, and the sodium bicarbonate cotransporter (NBCe1) in proximal tubules; sodium-potassium-chloride (NKCC2) cotransporter and $\mathrm{Na} / \mathrm{K}$ ATPase in the loop of Henle; and amiloride-sensitive sodium channel $(\mathrm{ENaC})$ in distal tubules, all of which increases sodium reabsorption in the kidneys, causing water-sodium retention and subsequent cardiac dysfunction [25]. Therefore, aside from the cellular memory properties induced by high glucose stimulation, the side effects of hypoglycemic drugs may also play a role in the HGM phenomenon in diabetic cardiomyopathy.

\section{Conclusions and perspectives}

The mechanisms that underlie the HGM phenomenon has not been fully understood thus far. Numerous studies have suggested that multiple molecular pathways, such as AGEs, oxidative stress, and epigenetic modification, might be involved in this process. However, these mechanisms do not seem to exist in isolation but form a complex network in which these components exert mutual regulatory effects, forming various vicious cycles (Fig. 3). The abnormal metabolism caused by high glucose levels causes mitochondrial oxidative stress. For example, ROS overproduction inhibits the activity of glyceraldehyde-3phosphate dehydrogenase and leads to the accumulation of glycolytic intermediates, which then activate the polyol and hexosamine pathways, causing the activation of the protein kinase $\mathrm{C}-\beta$ (PKC- $\beta$ ) pathway and the formation of AGEs [120,121]. AGEs promote ROS production in myocytes, thus forming a vicious cycle between ROS

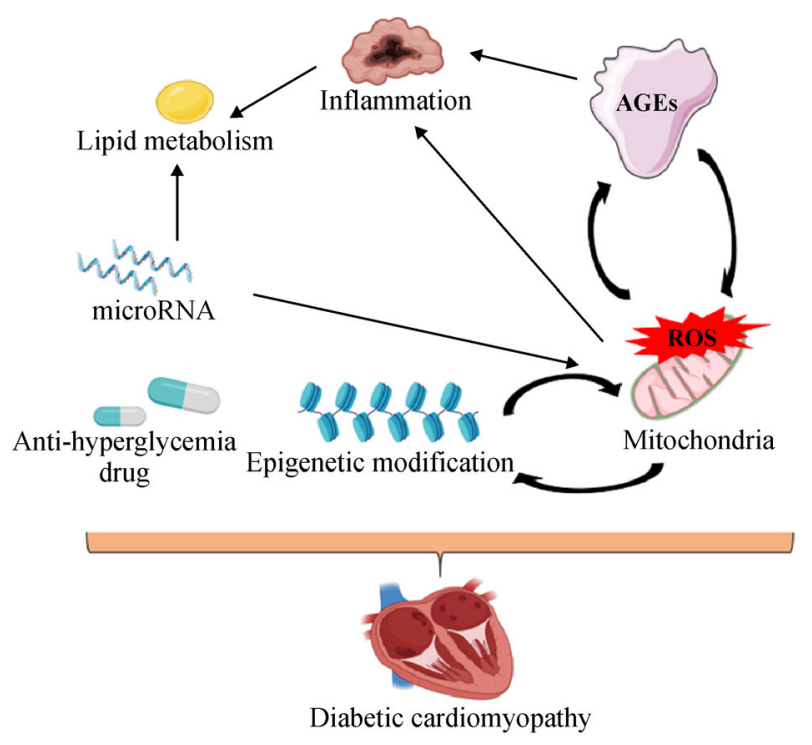

Fig. 3 Various pathogenic mechanisms by which diabetic cardiomyopathy (DCM) forms a complex network. and AGEs. In addition, ROS can induce various posttranslational modifications of histones, such as acetylation, methylation, phosphorylation, and ubiquitination. Even if hypoglycemic treatment is able to restore the glucose metabolism pathway to its normal state and leads to ROS production, most epigenetic modifications are irreversible, causing persistent abnormal expression patterns of multiple genes (including ROS-related genes), and ultimately contributing to the progressive worsening of myocardial function $[103,122]$. The abnormal expression of miRNAs can also further lead to mitochondrial dysfunction and ROS overproduction [72].

The pathogenic molecules mentioned above form a complex interlocking network. However, which molecules in these pathogenetic processes are the most critical and initiating factors remain unclear. Therefore, further time point studies are warranted to unveil the earliest signal molecule and the key abnormal pathways in diabetic cardiomyopathy. Other important pathways are also involved in diabetic cardiomyopathy. For instance, although the glucose within diabetic cardiomyocytes shows reduced flux through glycolysis, it actually participates in more than one carbon cycling pathways, as well as in multiple glycolytic side branch pathways, such as the polyol pathway, the hexosamine biosynthetic pathway, and the pentose phosphate pathway [58]. These pathways are crucial to the O-17 GlcNAc modification of proteins and alteration of relative protein function or stability [123-126]. However, compared with the wellstudied irreversible AGE modifications, the role of dynamic and enzymatic O-GlcNAcylation in hyperglycemic memory remains unclear and requires further study.

Sustained high glucose stress despite subsequent normoglycemia is not limited to diabetic cardiomyopathy. The HGM phenomenon is a common phenomenon in various diabetic complications, such as nephropathy and retinopathy $[127,128]$, which were not included in this review because our focus was on cardiovascular complications. Diabetic damages in various target organs and cell types have been indicated to be quite different. For instance, in diabetic nephropathy and retinopathy, persistent hyperglycemic stress on endothelial cells plays a pivotal role. By comparison, in diabetic cardiomyopathy, various cells, such as cardiomyocytes, myocardial microvascular endothelial cells, fibroblasts, and immune cells, may jointly participate in the pathogenesis of the HGM phenomenon. Previous studies have also revealed that intensive glucose control effectively lowers the risk of myocardial infarction/coronary artery disease, further supporting different pathogenesis in different target organs/cells suffering from the HGM phenomenon.

Although the HGM phenomenon has been confirmed by substantial clinical and experimental studies, intensive glucose control at the early stage can indeed be able to 
bring benefits for diabetic complications. For instance, the incidence of cardiovascular diseases in type 1 diabetes patients is reduced if intensive glycemic control is provided soon after diagnosis [129]. Preclinical experiments have also suggested that good control of blood glucose soon after the induction of diabetes offers protective effects against retinopathy, neuropathy, or oxidative and nitrative stress [130-132]. These findings highlighted the concept of "point of no return," which occurs during the process of diabetes mellitus and related complications, beyond which the onset of good glycemic control would be no longer sufficient to revert pathological changes in target cells and organs, leading to failure in preventing some of the diabetic end point events.

Future studies should focus on exploring the unique mechanism of the HGM phenomenon in different organs/ cells, as well as in cell-cell interactions. A profound elucidation of the temporal and spatial changes in this process would assist in providing novel insights into the prevention and treatment of diabetes complications.

\section{Acknowledgements}

We thank our colleagues in the group of Dao Wen Wang for stimulating discussions. This work was supported by grants from the National Natural Science Foundation of China (Nos. 81822002, 31771264, and 31800973) and the Fundamental Research Funds for the Central Universities (No. 2019kfyXMBZ035). The funders had no role in study design, data collection and analysis, manuscript preparation, or decision to publish.

\section{Compliance with ethics guidelines}

Jiabing Zhan, Chen Chen, Dao Wen Wang, and Huaping Li declare no conflicts of interest. This manuscript is a review and does not involve a research protocol requiring approval by the relevant institutional review board or ethics committee.

Open Access This article is licensed under a Creative Commons Attribution 4.0 International License, which permits use, sharing, adaptation, distribution and reproduction in any medium or format, as long as you give appropriate credit to the original author(s) and the source, provide a link to the Creative Commons license, and indicate if changes were made.

The images or other third party material in this article are included in the article's Creative Commons license, unless indicated otherwise in a credit line to the material. If material is not included in the article's Creative Commons license and your intended use is not permitted by statutory regulation or exceeds the permitted use, you will need to obtain permission directly from the copyright holder.

To view a copy of this license, visit https://creativecommons.org/ licenses/by/4.0/.

\section{References}

1. Fang ZY, Prins JB, Marwick TH. Diabetic cardiomyopathy: evidence, mechanisms, and therapeutic implications. Endocr Rev 2004; 25(4): 543-567

2. Farhangkhoee H, Khan ZA, Kaur H, Xin X, Chen S, Chakrabarti S. Vascular endothelial dysfunction in diabetic cardiomyopathy: pathogenesis and potential treatment targets. Pharmacol Ther 2006; 111(2): 384-399

3. Fonarow GC. An approach to heart failure and diabetes mellitus. Am J Cardiol 2005; 96(4 Supplement): 47-52

4. Haffner S, Taegtmeyer H. Epidemic obesity and the metabolic syndrome. Circulation 2003; 108(13): 1541-1545

5. Hsueh W, Abel ED, Breslow JL, Maeda N, Davis RC, Fisher EA, Dansky H, McClain DA, McIndoe R, Wassef MK, Rabadán-Diehl C, Goldberg IJ. Recipes for creating animal models of diabetic cardiovascular disease. Circ Res 2007; 100(10): 1415-1427

6. Hamby RI, Zoneraich S, Sherman L. Diabetic cardiomyopathy. JAMA 1974; 229(13): 1749-1754

7. Cosson S, Kevorkian JP. Left ventricular diastolic dysfunction: an early sign of diabetic cardiomyopathy? Diabetes Metab 2003; 29 (5): 455-466

8. Jia G, Hill MA, Sowers JR. Diabetic cardiomyopathy: an update of mechanisms contributing to this clinical entity. Circ Res 2018; 122 (4): 624-638

9. Lee WS, Kim J. Application of animal models in diabetic cardiomyopathy. Diabetes Metab J 2021; 45(2): 129-145

10. Aneja A, Tang WH, Bansilal S, Garcia MJ, Farkouh ME. Diabetic cardiomyopathy: insights into pathogenesis, diagnostic challenges, and therapeutic options. Am J Med 2008; 121(9): 748-757

11. Miki T, Yuda S, Kouzu H, Miura T. Diabetic cardiomyopathy: pathophysiology and clinical features. Heart Fail Rev 2013; 18(2): 149-166

12. Li H, Fan J, Chen C, Wang DW. Subcellular microRNAs in diabetic cardiomyopathy. Ann Trans1 Med 2020; 8(23): 1602

13. Lee MMY, McMurray JJV, Lorenzo-Almorós A, Kristensen SL, Sattar N, Jhund PS, Petrie MC. Diabetic cardiomyopathy. Heart 2019; 105(4): 337-345

14. Ren J, Ceylan-Isik AF. Diabetic cardiomyopathy: do women differ from men? Endocrine 2004; 25(2): 73-83

15. Ren J, Sowers JR. Application of a novel curcumin analog in the management of diabetic cardiomyopathy. Diabetes 2014; 63(10): 3166-3168

16. Bi Y, Zhang Y, Ren J. Phosphoinositide 3-kinase therapy in diabetic cardiomyopathy: unravelling an enigma. Am J Physiol Heart Circ Physiol 2020; 318(5): H1029-H1031

17. Yang L, Zhao D, Ren J, Yang J. Endoplasmic reticulum stress and protein quality control in diabetic cardiomyopathy. Biochim Biophys Acta 2015; 1852(2): 209-218

18. .Diabetes Control and Complications Trial Research Group, Nathan DM, Genuth S, Lachin J, Cleary P, Crofford O, Davis M, Rand L, Siebert C. The effect of intensive treatment of diabetes on the development and progression of long-term complications in insulin-dependent diabetes mellitus. N Engl J Med 1993; 329(14): 977-986

19. Afroz A, Ali L, Karim MN, Alramadan MJ, Alam K, Magliano DJ, Billah B. Glycaemic control for people with type 2 diabetes 
mellitus in Bangladesh - an urgent need for optimization of management plan. Sci Rep 2019; 9(1): 10248

20. Fincke BG, Clark JA, Linzer M, Spiro A 3rd, Miller DR, Lee A, Kazis LE. Assessment of long-term complications due to type 2 diabetes using patient self-report: the diabetes complications index. J Ambul Care Manage 2005; 28(3): 262-273

21. Stettler C, Allemann S, Jüni $P$, Cull CA, Holman RR, Egger M, Krähenbühl S, Diem P. Glycemic control and macrovascular disease in types 1 and 2 diabetes mellitus: meta-analysis of randomized trials. Am Heart J 2006; 152(1): 27-38

22. UK Prospective Diabetes Study (UKPDS) Group. Effect of intensive blood-glucose control with metformin on complications in overweight patients with type 2 diabetes (UKPDS 34). Lancet 1998; 352(9131): 854-865

23. UK Prospective Diabetes Study (UKPDS) Group. Intensive bloodglucose control with sulphonylureas or insulin compared with conventional treatment and risk of complications in patients with type 2 diabetes (UKPDS 33). Lancet 1998; 352(9131): 837-853

24. Control Group, Turnbull FM, Abraira C, Anderson RJ, Byington RP, Chalmers JP, Duckworth WC, Evans GW, Gerstein HC, Holman RR, Moritz TE, Neal BC, Ninomiya T, Patel AA, Paul SK, Travert F, Woodward M. Intensive glucose control and macrovascular outcomes in type 2 diabetes. Diabetologia 2009; 52(11): 2288-2298

25. Gilbert RE, Krum H. Heart failure in diabetes: effects of antihyperglycaemic drug therapy. Lancet 2015; 385(9982): 2107-2117

26. Gugliucci A. Formation of fructose-mediated advanced glycation end products and their roles in metabolic and inflammatory diseases. Adv Nutr 2017; 8(1): 54-62

27. Davis KE, Prasad C, Vijayagopal P, Juma S, Imrhan V. Advanced glycation end products, inflammation, and chronic metabolic diseases: links in a chain? Crit Rev Food Sci Nutr 2016; 56(6): 989-998

28. Ma H, Li SY, Xu P, Babcock SA, Dolence EK, Brownlee M, Li J, Ren J. Advanced glycation endproduct (AGE) accumulation and AGE receptor (RAGE) up-regulation contribute to the onset of diabetic cardiomyopathy. J Cell Mol Med 2009; 13(8b): 17511764

29. Brownlee M. Glycation products and the pathogenesis of diabetic complications. Diabetes Care 1992; 15(12): 1835-1843

30. Oldfield MD, Bach LA, Forbes JM, Nikolic-Paterson D, McRobert A, Thallas V, Atkins RC, Osicka T, Jerums G, Cooper ME. Advanced glycation end products cause epithelial-myofibroblast transdifferentiation via the receptor for advanced glycation end products (RAGE). J Clin Invest 2001; 108(12): 1853-1863

31. Jin X, Yao T, Zhou Z, Zhu J, Zhang S, Hu W, Shen C. Advanced glycation end products enhance macrophages polarization into M1 phenotype through activating RAGE/NF- $\mathrm{B}$ pathway. Biomed Res Int 2015; 2015: 732450

32. Bucala R, Tracey KJ, Cerami A. Advanced glycosylation products quench nitric oxide and mediate defective endothelium-dependent vasodilatation in experimental diabetes. J Clin Invest 1991; 87(2): 432-438

33. Schmidt AM, Hori O, Chen JX, Li JF, Crandall J, Zhang J, Cao R, Yan SD, Brett J, Stern D. Advanced glycation endproducts interacting with their endothelial receptor induce expression of vascular cell adhesion molecule-1 (VCAM-1) in cultured human endothelial cells and in mice. A potential mechanism for the accelerated vasculopathy of diabetes. J Clin Invest 1995; 96(3): 1395-1403

34. Wang J, Tang Z, Zhang Y, Qiu C, Zhu L, Zhao N, Liu Z. Matrine alleviates AGEs-induced cardiac dysfunctions by attenuating calcium overload via reducing ryanodine receptor 2 activity. Eur J Pharmacol 2019; 842: 118-124

35. Tian C, Alomar F, Moore CJ, Shao CH, Kutty S, Singh J, Bidasee KR. Reactive carbonyl species and their roles in sarcoplasmic reticulum $\mathrm{Ca}^{2+}$ cycling defect in the diabetic heart. Heart Fail Rev 2014; 19(1): 101-112

36. Hamilton S, Terentyev D. Altered intracellular calcium homeostasis and arrhythmogenesis in the aged heart. Int J Mol Sci 2019; 20(10): 2386

37. Yang YC, Tsai CY, Chen CL, Kuo CH, Hou CW, Cheng SY, Aneja R, Huang CY, Kuo WW. Pkc $\delta$ activation is involved in ROS-mediated mitochondrial dysfunction and apoptosis in cardiomyocytes exposed to advanced glycation end products (Ages). Aging Dis 2018; 9(4): 647-663

38. Bucala R, Mitchell R, Arnold K, Innerarity T, Vlassara H, Cerami A. Identification of the major site of apolipoprotein $\mathrm{B}$ modification by advanced glycosylation end products blocking uptake by the low density lipoprotein receptor. J Biol Chem 1995; 270(18): 10828-10832

39. Zoltowska M, Delvin E, Ziv E, Peretti N, Chartré M, Levy E. Impact of in vivo glycation of LDL on platelet aggregation and monocyte chemotaxis in diabetic psammomys obesus. Lipids 2004; 39(1): 81-85

40. Chaudhuri J, Bains Y, Guha S, Kahn A, Hall D, Bose N, Gugliucci A, Kapahi P. The role of advanced glycation end products in aging and metabolic diseases: bridging association and causality. Cell Metab 2018; 28(3): 337-352

41. Nowotny K, Grune T. Degradation of oxidized and glycoxidized collagen: role of collagen cross-linking. Arch Biochem Biophys 2014; 542: 56-64

42. Fishman SL, Sonmez H, Basman C, Singh V, Poretsky L. The role of advanced glycation end-products in the development of coronary artery disease in patients with and without diabetes mellitus: a review. Mol Med 2018; 24(1): 59

43. Li H, Fan J, Zhao Y, Zhang X, Dai B, Zhan J, Yin Z, Nie X, Fu XD, Chen C, Wang DW. Nuclear miR-320 mediates diabetes-induced cardiac dysfunction by activating transcription of fatty acid metabolic genes to cause lipotoxicity in the heart. Circ Res 2019; 125(12): 1106-1120

44. Zhang X, Zuo X, Yang B, Li Z, Xue Y, Zhou Y, Huang J, Zhao X, Zhou J, Yan Y, Zhang H, Guo P, Sun H, Guo L, Zhang Y, Fu XD. MicroRNA directly enhances mitochondrial translation during muscle differentiation. Cell 2014; 158(3): 607-619

45. Lu TX, Rothenberg ME. MicroRNA. J Allergy Clin Immunol 2018; 141(4): 1202-1207

46. Zhong X, Liao Y, Chen L, Liu G, Feng Y, Zeng T, Zhang J. The microRNAs in the pathogenesis of metabolic memory. Endocrinology 2015; 156(9): 3157-3168

47. Li J, Donath S, Li Y, Qin D, Prabhakar BS, Li P. miR-30 regulates mitochondrial fission through targeting p53 and the dynaminrelated protein-1 pathway. PLoS Genet 2010; 6(1): e1000795

48. van Rooij E, Sutherland LB, Thatcher JE, DiMaio JM, Naseem 
RH, Marshall WS, Hill JA, Olson EN. Dysregulation of microRNAs after myocardial infarction reveals a role of miR-29 in cardiac fibrosis. Proc Natl Acad Sci USA 2008; 105(35): 13027 13032

49. Strycharz J, Świderska E, Wróblewski A, Podolska M, Czarny P, Szemraj J, Balcerczyk A, Drzewoski J, Kasznicki J, Śliwińska A. Hyperglycemia affects miRNAs expression pattern during adipogenesis of human visceral adipocytes - is memorization involved? Nutrients 2018; 10(11): 1774

50. Peng QH, Tong P, Gu LM, Li WJ. Astragalus polysaccharide attenuates metabolic memory-triggered ER stress and apoptosis via regulation of miR-204/SIRT1 axis in retinal pigment epithelial cells. Biosci Rep 2020; 40(1): BSR20192121

51. Costantino S, Paneni F, Lüscher TF, Cosentino F. MicroRNA profiling unveils hyperglycaemic memory in the diabetic heart. Eur Heart J 2016; 37(6): 572-576

52. Hussain S, Khan AW, Akhmedov A, Suades R, Costantino S, Paneni F, Caidahl K, Mohammed SA, Hage C, Gkolfos C, Björck H, Pernow J, Lund LH, Lüscher TF, Cosentino F. Hyperglycemia induces myocardial dysfunction via epigenetic regulation of JunD. Circ Res 2020; 127(10): 1261-1273

53. Tong M, Sadoshima J. Nuclear miR-320 controls lipotoxicity. Circ Res 2019; 125(12): 1121-1123

54. Matough FA, Budin SB, Hamid ZA, Alwahaibi N, Mohamed J. The role of oxidative stress and antioxidants in diabetic complications. Sultan Qaboos Univ Med J 2012; 12(1): 5-18

55. Kuroki T, Isshiki K, King GL. Oxidative stress: the lead or supporting actor in the pathogenesis of diabetic complications. J Am Soc Nephrol 2003; 14(Suppl 3): S216-S220

56. Wang D, Yin Y, Wang S, Zhao T, Gong F, Zhao Y, Wang B, Huang Y, Cheng Z, Zhu G, Wang Z, Wang Y, Ren J, Liang G, Li $X$, Huang Z. FGF1 ${ }^{\Delta \text { HBS }}$ prevents diabetic cardiomyopathy by maintaining mitochondrial homeostasis and reducing oxidative stress via AMPK/Nur77 suppression. Signal Transduct Target Ther 2021; 6(1): 133

57. Wende AR, Schell JC, Ha CM, Pepin ME, Khalimonchuk O, Schwertz H, Pereira RO, Brahma MK, Tuinei J, Contreras-Ferrat A, Wang L, Andrizzi CA, Olsen CD, Bradley WE, Dell'Italia LJ, Dillmann WH, Litwin SE, Abel ED. Maintaining myocardial glucose utilization in diabetic cardiomyopathy accelerates mitochondrial dysfunction. Diabetes 2020; 69(10): 2094-2111

58. Maack C, Lehrke M, Backs J, Heinzel FR, Hulot JS, Marx N, Paulus WJ, Rossignol P, Taegtmeyer H, Bauersachs J, BayesGenis A, Brutsaert D, Bugger H, Clarke K, Cosentino F, De Keulenaer G, Dei Cas A, González A, Huelsmann M, Iaccarino G, Lunde IG, Lyon AR, Pollesello P, Rena G, Riksen NP, Rosano G, Staels B, van Laake LW, Wanner C, Farmakis D, Filippatos G, Ruschitzka F, Seferovic P, de Boer RA, Heymans S. Heart failure and diabetes: metabolic alterations and therapeutic interventions: a state-of-the-art review from the Translational Research Committee of the Heart Failure Association-European Society of Cardiology. Eur Heart J 2018; 39(48): 4243-4254

59. Jubaidi FF, Zainalabidin S, Mariappan V, Budin SB. Mitochondrial dysfunction in diabetic cardiomyopathy: the possible therapeutic roles of phenolic acids. Int J Mol Sci 2020; 21(17): 6043

60. van de Weijer T, Schrauwen-Hinderling VB, Schrauwen P.
Lipotoxicity in type 2 diabetic cardiomyopathy. Cardiovasc Res 2011; 92(1): 10-18

61. Trumpower BL. The protonmotive Q cycle. Energy transduction by coupling of proton translocation to electron transfer by the cytochrome bc1 complex. J Biol Chem 1990; 265(20): 1140911412

62. Wallace D C. Diseases of the mitochondrial DNA. Annu Rev Biochem 1992; 61: 1175-1212

63. Giacco F, Brownlee M. Oxidative stress and diabetic complications. Circ Res 2010; 107(9): 1058-1070

64. Craven PA, Davidson CM, DeRubertis FR. Increase in diacylglycerol mass in isolated glomeruli by glucose from de novo synthesis of glycerolipids. Diabetes 1990; 39(6): 667-674

65. Ihnat MA, Thorpe JE, Kamat CD, Szabó C, Green DE, Warnke LA, Lacza Z, Cselenyák A, Ross K, Shakir S, Piconi L, Kaltreider RC, Ceriello A. Reactive oxygen species mediate a cellular 'memory' of high glucose stress signalling. Diabetologia 2007; 50 (7): 1523-1531

66. Cosentino F, Francia P, Camici GG, Pelicci PG, Lüscher TF, Volpe M. Final common molecular pathways of aging and cardiovascular disease: role of the p66Shc protein. Arterioscler Thromb Vasc Biol 2008; 28(4): 622-628

67. Rota M, LeCapitaine N, Hosoda T, Boni A, De Angelis A, PadinIruegas ME, Esposito G, Vitale S, Urbanek K, Casarsa C, Giorgio M, Lüscher TF, Pelicci PG, Anversa P, Leri A, Kajstura J. Diabetes promotes cardiac stem cell aging and heart failure, which are prevented by deletion of the $\mathrm{p} 66^{\text {shc }}$ gene. Circ Res 2006; 99(1): $42-52$

68. Paneni F, Mocharla P, Akhmedov A, Costantino S, Osto E, Volpe M, Lüscher TF, Cosentino F. Gene silencing of the mitochondrial adaptor $\mathrm{p} 66^{\mathrm{Shc}}$ suppresses vascular hyperglycemic memory in diabetes. Circ Res 2012; 111(3): 278-289

69. Paneni F, Volpe M, Lüscher TF, Cosentino F. SIRT1, p66 ${ }^{\text {Shc }}$, and Set7/9 in vascular hyperglycemic memory: bringing all the strands together. Diabetes 2013; 62(6): 1800-1807

70. Lee JY, Lee YJ, Jeon HY, Han ET, Park WS, Hong SH, Kim YM, Ha KS. The vicious cycle between transglutaminase 2 and reactive oxygen species in hyperglycemic memory-induced endothelial dysfunction. FASEB J 2019; 33(11): 12655-12667

71. Isabelle $M$, Vergeade A, Moritz F, Dautréaux B, Henry JP, Lallemand F, Richard V, Mulder P, Thuillez C, Monteil C. NADPH oxidase inhibition prevents cocaine-induced up-regulation of xanthine oxidoreductase and cardiac dysfunction. J Mol Cell Cardiol 2007; 42(2): 326-332

72. Li H, Dai B, Fan J, Chen C, Nie X, Yin Z, Zhao Y, Zhang X, Wang D W. The different roles of miRNA-92a-2-5p and let-7b-5p in mitochondrial translation in $\mathrm{db} / \mathrm{db}$ Mice. Mol Ther Nucleic Acids 2019; 17: 424-435

73. Climent M, Viggiani G, Chen YW, Coulis G, Castaldi A. MicroRNA and ROS crosstalk in cardiac and pulmonary diseases. Int J Mol Sci 2020; 21(12): 4370

74. Kim J H, Park S G, Song S Y, Kim J K, Sung J H. Reactive oxygen species-responsive miR-210 regulates proliferation and migration of adipose-derived stem cells via PTPN2. Cell Death Dis 2013; 4: e588

75. He J, Xu Q, Jing Y, Agani F, Qian X, Carpenter R, Li Q, Wang XR, Peiper SS, Lu Z, Liu LZ, Jiang BH. Reactive oxygen species 
regulate ERBB2 and ERBB3 expression via miR-199a/125b and DNA methylation. EMBO Rep 2012; 13(12): 1116-1122

76. West AP, Shadel GS. Mitochondrial DNA in innate immune responses and inflammatory pathology. Nat Rev Immunol 2017; 17 (6): 363-375

77. Jayaraman S. Epigenetic mechanisms of metabolic memory in diabetes. Circ Res 2012; 110(8): 1039-1041

78. Cencioni C, Spallotta F, Greco S, Martelli F, Zeiher A M, Gaetano C. Epigenetic mechanisms of hyperglycemic memory. Int $\mathrm{J}$ Biochem Cell Biol 2014; 51: 155-158

79. Tahiliani M, Koh KP, Shen Y, Pastor WA, Bandukwala H, Brudno Y, Agarwal S, Iyer LM, Liu DR, Aravind L, Rao A. Conversion of 5-methylcytosine to 5-hydroxymethylcytosine in mammalian DNA by MLL partner TET1. Science 2009; 324(5929): 930-935

80. Xiao M, Yang H, Xu W, Ma S, Lin H, Zhu H, Liu L, Liu Y, Yang C, Xu Y, Zhao S, Ye D, Xiong Y, Guan KL. Inhibition of $\alpha-K G-$ dependent histone and DNA demethylases by fumarate and succinate that are accumulated in mutations of $\mathrm{FH}$ and $\mathrm{SDH}$ tumor suppressors. Genes Dev 2012; 26(12): 1326-1338

81. Serena C, Ceperuelo-Mallafré V, Keiran N, Queipo-Ortuño MI, Bernal R, Gomez-Huelgas R, Urpi-Sarda M, Sabater M, PérezBrocal V, Andrés-Lacueva C, Moya A, Tinahones FJ, FernándezReal JM, Vendrell J, Fernández-Veledo S. Elevated circulating levels of succinate in human obesity are linked to specific gut microbiota. ISME J 2018; 12(7): 1642-1657

82. Kim M. DNA methylation: a cause and consequence of type 2 diabetes. Genomics Inform 2019; 17(4): e38

83. Su X, Wellen K E, Rabinowitz J D. Metabolic control of methylation and acetylation. Curr Opin Chem Biol 2016; 30: $52-60$

84. Peterson CL, Laniel MA. Histones and histone modifications. Curr Biol 2004; 14(14): R546-R551

85. Granger A, Abdullah I, Huebner F, Stout A, Wang T, Huebner T, Epstein JA, Gruber PJ. Histone deacetylase inhibition reduces myocardial ischemia-reperfusion injury in mice. FASEB J 2008; 22 (10): 3549-3560

86. Chen Y, Du J, Zhao Y T, Zhang L, Lv G, Zhuang S, Qin G, Zhao T C. Histone deacetylase (HDAC) inhibition improves myocardial function and prevents cardiac remodeling in diabetic mice. Cardiovasc Diabetol 2015; 14: 99

87. Yu XY, Geng YJ, Liang JL, Lin QX, Lin SG, Zhang S, Li Y. High levels of glucose induce apoptosis in cardiomyocyte via epigenetic regulation of the insulin-like growth factor receptor. Exp Cell Res 2010; 316(17): 2903-2909

88. Wang M, Hu J, Yan L, Yang Y, He M, Wu M, Li Q, Gong W, Yang Y, Wang Y, Handy DE, Lu B, Hao C, Wang Q, Li Y, Hu R, Stanton RC, Zhang Z. High glucose-induced ubiquitination of G6PD leads to the injury of podocytes. FASEB J 2019; 33(5): 6296-6310

89. Vogelauer M, Krall AS, McBrian MA, Li JY, Kurdistani SK. Stimulation of histone deacetylase activity by metabolites of intermediary metabolism. J Biol Chem 2012; 287(38): 3200632016

90. Kouzarides T. Acetylation: a regulatory modification to rival phosphorylation? EMBO J 2000; 19(6): 1176-1179

91. Yu W, Gao B, Li N, Wang J, Qiu C, Zhang G, Liu M, Zhang R, Li C, Ji G, Zhang Y. Sirt3 deficiency exacerbates diabetic cardiac dysfunction: role of Foxo3A-Parkin-mediated mitophagy. Biochim
Biophys Acta Mol Basis Dis 2017; 1863(8): 1973-1983

92. Rossini A, Frati C, Lagrasta C, Graiani G, Scopece A, Cavalli S, Musso E, Baccarin M, Di Segni M, Fagnoni F, Germani A, Quaini E, Mayr M, Xu Q, Barbuti A, DiFrancesco D, Pompilio G, Quaini F, Gaetano C, Capogrossi MC. Human cardiac and bone marrow stromal cells exhibit distinctive properties related to their origin. Cardiovasc Res 2011; 89(3): 650-660

93. Wagner GR, Payne RM. Widespread and enzyme-independent $\mathrm{N} \varepsilon$ acetylation and $\mathrm{N} \varepsilon$-succinylation of proteins in the chemical conditions of the mitochondrial matrix. J Biol Chem 2013; 288 (40): 29036-29045

94. Narita T, Weinert BT, Choudhary C. Functions and mechanisms of non-histone protein acetylation. Nat Rev Mol Cell Biol 2019; 20 (3): 156-174

95. Kumar S, Kim YR, Vikram A, Naqvi A, Li Q, Kassan M, Kumar V, Bachschmid MM, Jacobs JS, Kumar A, Irani K. Sirtuin1regulated lysine acetylation of p66Shc governs diabetes-induced vascular oxidative stress and endothelial dysfunction. Proc Natl Acad Sci USA 2017; 114(7): 1714-1719

96. Huang T, Li X, Wang F, Lu L, Hou W, Zhu M, Miao C. The CREB/KMT5A complex regulates PTP1B to modulate high glucose-induced endothelial inflammatory factor levels in diabetic nephropathy. Cell Death Dis 2021; 12(4): 333

97. Wang J, Shen X, Liu J, Chen W, Wu F, Wu W, Meng Z, Zhu M, Miao C. High glucose mediates NLRP3 inflammasome activation via upregulation of ELF3 expression. Cell Death Dis 2020; 11(5): 383

98. Zhang H, Gao Q, Tan S, You J, Lyu C, Zhang Y, Han M, Chen Z, Li J, Wang H, Liao L, Qin J, Li J, Wong J. SET8 prevents excessive DNA methylation by methylation-mediated degradation of UHRF1 and DNMT1. Nucleic Acids Res 2019; 47(17): 90539068

99. Miao F, Chen Z, Genuth S, Paterson A, Zhang L, Wu X, Li SM, Cleary P, Riggs A, Harlan DM, Lorenzi G, Kolterman O, Sun W, Lachin JM, Natarajan R; DCCT/EDIC Research Group. Evaluating the role of epigenetic histone modifications in the metabolic memory of type 1 diabetes. Diabetes 2014; 63(5): 1748-1762

100. Chen Z, Miao F, Paterson AD, Lachin JM, Zhang L, Schones DE, Wu X, Wang J, Tompkins JD, Genuth S, Braffett BH, Riggs AD; DCCT/EDIC Research Group, Natarajan R. Epigenomic profiling reveals an association between persistence of DNA methylation and metabolic memory in the DCCT/EDIC type 1 diabetes cohort. Proc Natl Acad Sci USA 2016; 113(21): E3002-E3011

101. Olsen AS, Sarras MP Jr, Leontovich A, Intine RV. Heritable transmission of diabetic metabolic memory in zebrafish correlates with DNA hypomethylation and aberrant gene expression. Diabetes 2012; 61(2): 485-491

102. Brasacchio D, Okabe J, Tikellis C, Balcerczyk A, George P, Baker EK, Calkin AC, Brownlee M, Cooper ME, El-Osta A. Hyperglycemia induces a dynamic cooperativity of histone methylase and demethylase enzymes associated with gene-activating epigenetic marks that coexist on the lysine tail. Diabetes 2009; 58(5): 12291236

103. El-Osta A, Brasacchio D, Yao D, Pocai A, Jones PL, Roeder RG, Cooper ME, Brownlee M. Transient high glucose causes persistent epigenetic changes and altered gene expression during subsequent normoglycemia. J Exp Med 2008; 205(10): 2409-2417 
104. Pinney SE, Simmons RA. Epigenetic mechanisms in the development of type 2 diabetes. Trends Endocrinol Metab 2010; 21(4): 223-229

105. Siebel AL, Fernandez AZ, El-Osta A. Glycemic memory associated epigenetic changes. Biochem Pharmacol 2010; 80 (12): 1853-1859

106. Okabe J, Orlowski C, Balcerczyk A, Tikellis C, Thomas MC, Cooper ME, El-Osta A. Distinguishing hyperglycemic changes by Set7 in vascular endothelial cells. Circ Res 2012; 110(8): 10671076

107. Yu XY, Geng YJ, Liang JL, Zhang S, Lei HP, Zhong SL, Lin QX, Shan ZX, Lin SG, Li Y. High levels of glucose induce "metabolic memory" in cardiomyocyte via epigenetic histone H3 lysine 9 methylation. Mol Biol Rep 2012; 39(9): 8891-8898

108. Miao F, Gonzalo IG, Lanting L, Natarajan R. In vivo chromatin remodeling events leading to inflammatory gene transcription under diabetic conditions. J Biol Chem 2004; 279(17): 1809118097

109. Miao F, Smith DD, Zhang L, Min A, Feng W, Natarajan R. Lymphocytes from patients with type 1 diabetes display a distinct profile of chromatin histone $\mathrm{H} 3$ lysine 9 dimethylation: an epigenetic study in diabetes. Diabetes 2008; 57(12): 3189-3198

110. Zheng Z, Chen H, Li J, Li T, Zheng B, Zheng Y, Jin H, He Y, Gu $\mathrm{Q}, \mathrm{Xu} \mathrm{X}$. Sirtuin 1-mediated cellular metabolic memory of high glucose via the LKB1/AMPK/ROS pathway and therapeutic effects of metformin. Diabetes 2012; 61(1): 217-228

111. Chen X, Wu Q, Jiang H, Wang J, Zhao Y, Xu Y, Zhu M. SET8 is involved in the regulation of hyperglycemic memory in human umbilical endothelial cells. Acta Biochim Biophys Sin (Shanghai) 2018; 50(7): 635-642

112. Zee BM, Levin RS, Xu B, LeRoy G, Wingreen NS, Garcia BA. In vivo residue-specific histone methylation dynamics. J Biol Chem 2010; 285(5): 3341-3350

113. Greer EL, Shi Y. Histone methylation: a dynamic mark in health, disease and inheritance. Nat Rev Genet 2012; 13(5): 343-357

114. Schotta G, Ebert A, Krauss V, Fischer A, Hoffmann J, Rea S, Jenuwein T, Dorn R, Reuter G. Central role of Drosophila SU (VAR)3-9 in histone H3-K9 methylation and heterochromatic gene silencing. EMBO J 2002; 21(5): 1121-1131

115. Rusché LN, Rine J. Conversion of a gene-specific repressor to a regional silencer. Genes Dev 2001; 15(8): 955-967

116. Owen DJ, Ornaghi P, Yang JC, Lowe N, Evans PR, Ballario P, Neuhaus D, Filetici P, Travers AA. The structural basis for the recognition of acetylated histone $\mathrm{H} 4$ by the bromodomain of histone acetyltransferase gcn5p. EMBO J 2000; 19(22): 61416149

117. Dodd IB, Micheelsen MA, Sneppen K, Thon G. Theoretical analysis of epigenetic cell memory by nucleosome modification. Cell 2007; 129(4): 813-822
118. Prattichizzo F, De Nigris V, Spiga R, Mancuso E, La Sala L, Antonicelli R, Testa R, Procopio A D, Olivieri F, Ceriello A. Inflammageing and metaflammation: the yin and yang of type 2 diabetes. Ageing Res Rev 2018; 41:1-17

119. Elia E, Ministrini S, Carbone F, Montecucco F. Diabetic cardiomyopathy and inflammation: development of hostile microenvironment resulting in cardiac damage. Minerva Cardioangiol 2021; [Epub ahead of print] doi: 10.23736/S0026-4725.20.05454-7

120. Brownlee M. Biochemistry and molecular cell biology of diabetic complications. Nature 2001; 414(6865): 813-820

121. Bianchi C, Miccoli R, Del Prato S. Hyperglycemia and vascular metabolic memory: truth or fiction? Curr Diab Rep 2013; 13(3): 403-410

122. Cooper ME, El-Osta A. Epigenetics: mechanisms and implications for diabetic complications. Circ Res 2010; 107(12): 1403-1413

123. Banerjee PS, Ma J, Hart GW. Diabetes-associated dysregulation of O-GlcNAcylation in rat cardiac mitochondria. Proc Natl Acad Sci USA 2015; 112(19): 6050-6055

124. Ngoh GA, Facundo HT, Zafir A, Jones SP. O-GlcNAc signaling in the cardiovascular system. Circ Res 2010; 107(2): 171-185

125. Ducheix S, Magre J, Cariou B, Prieur X. Chronic O-GlcNAcylation and diabetic cardiomyopathy: the bitterness of glucose. Front Endocrinol (Lausanne) 2018; 9: 642

126. Love DC, Krause MW, Hanover JA. O-GlcNAc cycling: emerging roles in development and epigenetics. Semin Cell Dev Biol 2010; 21(6): 646-654

127. Friedrichs P, Schlotterer A, Sticht C, Kolibabka M, Wohlfart P, Dietrich A, Linn T, Molema G, Hammes HP. Hyperglycaemic memory affects the neurovascular unit of the retina in a diabetic mouse model. Diabetologia 2017; 60(7): 1354-1358

128. Carney EF. Diabetic nephropathy: role of podocyte SHP-1 in hyperglycaemic memory. Nat Rev Nephrol 2016; 12(11): 650

129. Nathan DM, Cleary PA, Backlund JY, Genuth SM, Lachin JM, Orchard TJ, Raskin P, Zinman B; Diabetes Control and Complications Trial/Epidemiology of Diabetes Interventions and Complications (DCCT/EDIC) Study Research Group. Intensive diabetes treatment and cardiovascular disease in patients with type 1 diabetes. N Engl J Med 2005; 353(25): 2643-2653

130. Yorek MS, Obrosov A, Shevalye H, Lupachyk S, Harper MM, Kardon RH, Yorek MA. Effect of glycemic control on corneal nerves and peripheral neuropathy in streptozotocin-induced diabetic C57B1/6J mice. J Peripher Nerv Syst 2014; 19(3): 205217

131. Engerman RL, Kern TS. Progression of incipient diabetic retinopathy during good glycemic control. Diabetes 1987; 36(7): 808-812

132. Kowluru RA. Effect of reinstitution of good glycemic control on retinal oxidative stress and nitrative stress in diabetic rats. Diabetes 2003; 52(3): 818-823 